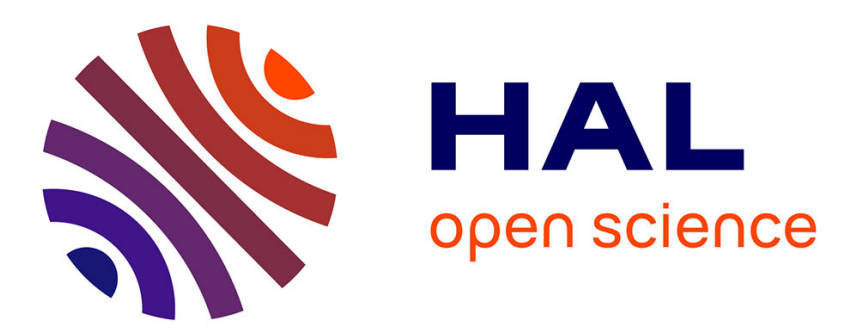

\title{
Linking performance pressure to employee work engagement: the moderating role of emotional stability
}

\author{
Yasir Mansoor Kundi, Shakir Sardar, Kamal Badar
}

\section{To cite this version:}

Yasir Mansoor Kundi, Shakir Sardar, Kamal Badar. Linking performance pressure to employee work engagement: the moderating role of emotional stability. Personnel Review, 2021, 10.1108/PR-052020-0313 . hal-03183363

\section{HAL Id: hal-03183363 https://hal-amu.archives-ouvertes.fr/hal-03183363}

Submitted on 29 Mar 2021

HAL is a multi-disciplinary open access archive for the deposit and dissemination of scientific research documents, whether they are published or not. The documents may come from teaching and research institutions in France or abroad, or from public or private research centers.
L'archive ouverte pluridisciplinaire HAL, est destinée au dépôt et à la diffusion de documents scientifiques de niveau recherche, publiés ou non, émanant des établissements d'enseignement et de recherche français ou étrangers, des laboratoires publics ou privés. 


\title{
Linking performance pressure to employee work engagement: the moderating role of emotional stability
}

\author{
Yasir Mansoor Kundi and Shakir Sardar \\ IAE Aix-Marseille Graduate School of Management, CERGAM, \\ Aix-Marseille University, Aix en Provence, France, and \\ Kamal Badar \\ School of Management, Victoria University of Wellington, Wellington, New Zealand
}

\begin{abstract}
Purpose - The purpose of this paper is to investigate the mediating role of threat and challenge appraisals in the relationship between performance pressure and employees' work engagement, as well as the buffering role of emotional stability, as a personal characteristic, in this process.

Design/methodology/approach - Data were collected using a three-wave research design. Hypotheses were examined with a sample of 247 white-collar employees from French organizations.

Findings - Performance pressure is appraised as either threat or challenge. Challenge appraisal positively mediated the performance pressure and work engagement relationship, whereas threat appraisal negatively mediated the performance pressure and work engagement relationship. Emotional stability moderated these effects, suggesting performance pressure was appraised as a challenge rather than a threat, which then enhanced employee work engagement.

Practical implications - This study has shown that employees with high emotional stability who perceived performance pressure as a challenge achieved stronger employee work engagement.

Originality/value - Building on Lazare's theory of stress and Mitchell et al.'s theorization, this research demonstrates mediating and moderating mechanisms driving the role of performance pressure on employee work engagement relationships.
\end{abstract}

Keywords Performance pressure, Threat appraisal, Challenge appraisal, Emotional stability, Work engagement

Paper type Research paper

\section{Introduction}

Work engagement - "a positive, fulfilling, work-related state of mind, that is characterized by vigor, dedication, and absorption" (Schaufeli et al., 2002, p. 74), has emerged as a significant construct in the management literature because it has been shown to promote a variety of not only the employee but also organizational outcomes. Job satisfaction, organizational citizenship behavior, organizational engagement and low turnover intentions (Aboramadan et al., 2020; Albrecht et al., 2020; Rai and Maheshwari, 2020) have been reported as the examples of these outcomes. The growing interest in work engagement gives rise to the need for a better understanding of its antecedents (Matsuo, 2019). Although numerous factors have been examined as antecedents (e.g. personality traits, learning goal orientation, personal resources and job autonomy), performance-related antecedents of work engagement have so far received very little attention in the existing literature. Only recently, research began to address questions concerning whether employees facing demands for high performance increase or decrease their work engagement (Mitchell et al., 2019; Zhang et al., 2017). Thus, only a narrow spectrum of the performance-related antecedents of work engagement has been considered, especially in terms of performance pressure. 
Performance pressure refers to "a belief that current performance is inadequate for achieving a desired goal, and a negative affective response linked to the attitude and associated belief" (Eisenberger and Aselage, 2009, p. 96). It also refers to the urgency to achieve high performance levels because performance outcomes are tied to substantial consequences (Mitchell et al., 2018). Research on performance pressure has revealed a contradictory set of consequences in that performance pressure seems to positively effect motivation and functional work behavior (Eisenberger and Aselage, 2009; Mitchell et al., 2019) but at the expense of increased stress and unethical behavior (Jensen et al., 2019). Challenge-hindrance model (Cavanaugh et al., 2000) has categorized stressors (i.e. antecedents of stress) into two categories: challenge stressors and hindrance stressors. The former refers to stressors that yield positive outcomes and gains for individuals, while the latter refers to stressors that do not yield positive outcomes or gain for the individuals (Cavanaugh et al., 1998). Furthermore, challenge-hindrance model considered both types of stressors as priori, assuming that most people appraise stressors in the same way. However, LePine et al. (2005) and Webster et al. (2011) contended that the difference between the relationship of challenge and hindrance stressors with employee job-related outcomes depends upon how individuals appraise these stressors. Accordingly, Lazarus and Folkman (1984) in their cognitive theory of stress argued that how individuals appraise a stressor can provoke different coping processes. When a stressor is appraised as a challenge, it creates an internal focus on the potential opportunities from the situation, whereas a stressor appraised as a threat creates an internal focus on the potential harm or strain associated with addressing the situation. Mitchell et al. (2019), in extending cognitive theory of stress, theorized that how individuals appraise performance pressure can elicits both functional and dysfunctional behavior. More specifically, they suggested that performance pressure is a unique source of work stress and is appraised by the employees either as a challenge or threat, which, in turn, determines whether the pressure will result in more functional vs dysfunctional behaviors.

Yet, while evidence indicates that performance pressure affects work engagement, less is known about why employees may be more or less inclined to respond to the pressure functionally. Variation in how performance pressure is appraised may explain why such positive or negative behaviors emerge (Mitchell et al., 2019). According to transactional theory of stress (Lazarus, 1966), stress reactions or processes are influenced by individuals' certain stable traits because some traits alter how individuals cognitively process information about stressors. Building on Lazarus' (1966) theory of stress with the tenets of Mitchell et al.'s (2019) theory, and responding to the call by Mitchell et al. (2019), we examine the moderating role of emotional stability (i.e. individual capability to adequately cope with negative emotions, such as anxiety, stress and anger; Alessandri et al., 2018) on the relationship between performance pressure and work engagement. Unlike other personality traits (e.g. conscientiousness, extraversion), emotional stability is not only more closely associated with job-related aspects of individual behavior (Oprea et al., 2019) but also has stronger ties with individuals' emotional and affective states, such as stress (Alessandri et al., 2018), exhaustion (Liu and Yu, 2019) and subjective wellbeing (Sobol-Kwapinska, 2016). Given that performance pressure may lead to emotion suppression instead of dealing with emotions (Ness et al., 2017), we argue that emotional stability may be more relevant in studying performance pressure and work engagement relationship.

Accordingly, our study contributes to the existing literature in several ways. First, it helps broaden the existing knowledge on the double-edged nature of performance pressure and is the first study to empirically examine work engagement in response to performance pressure via both threat and challenge appraisals and one of the few attempts to examine the role of coping strategy while dealing with performance pressure. Second, we contribute to the work engagement literature by examining how a single stressor can motivate different reactions, 
ultimately influencing employees' work engagement. Mitchell et al. (2019) argued that performance pressure is a unique and dynamic work stressor, appraised as either a threat or challenge, which, in turn leads to both positive and negative reactions. However, they only examined the effects of performance pressure on engagement through challenge appraisal ("an appraisal in which the perception of danger does not exceeds the perception of abilities or resources to cope with the stressor"; Tomaka et al., 1993, p. 248), whereas the question of whether threat appraisal ("an appraisal in which the perception of danger exceeds the perception of abilities or resources to cope with the stressor"; Tomaka et al., 1993, p. 248) influences employees' work engagement is still unanswered. We, therefore, extend the previous research and fulfill a research gap by examining the effects of performance pressure on work engagement through both threat and challenge appraisals.

Third, the present study adds to existing literature by examining the personality factor of emotional stability to understand its disparate moderating role on the effects of two types of appraisals, i.e. threat and challenge, on work engagement. Only few studies in the existing literature have examined the moderating factors of the relationship between performance pressure and its outcomes (e.g. Mitchell et al., 2019; Zhang et al., 2017). In a recent study, Mitchell et al. (2019) found positive moderating role of trait resilience on performance pressure and its outcomes but called for further research to explore other intervening mechanisms in that relationships. Thus, in response to the appeal by Mitchell et al. (2019) to explore the moderating role of different personality traits, specifically the role of emotional stability on the stress process triggered by performance pressure, the present study provides insight into the mechanisms that might explain why and when performance pressure affects employees' stress appraisals and, in turn, their subsequent work engagement. Figure 1 depicts our hypothesized model.

\section{Theoretical background and hypotheses development}

\section{Performance pressure, threat appraisal and work engagement}

Performance pressure is a subjective experience of "any factor or combination of factors that increase the importance of performing well" (Baumeister, 1984, p. 610). Rewards, punishments and competition in the workplace can produce the perception that meeting goals and achieving high levels of performance is highly important (Prouska et al., 2016), which is also referred to as performance pressure (Zhang et al., 2017). According to Gardner (2012), performance pressure is an external force imposed on employees to deliver a superior outcome and high levels of performance. The application of performance pressure is based on

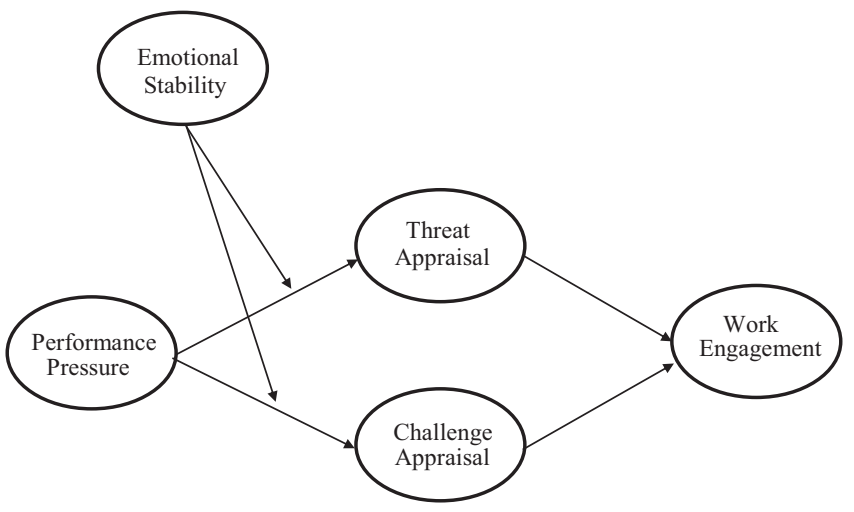

Figure 1. 
the belief that striving for high levels of performance is needed, which, in turn will lead to significant consequences (Mitchell et al., 2018; Tan et al., 2017). Performance pressure is different from other types of work stressors, such as pressures to speed up the completion of tasks or due to heavy workloads (Mitchell et al., 2019). Performance pressure is defined as the urgent demands or constraints placed on an individual to respond in a certain way (Baucus, 1994). More specifically, performance pressure can be defined as creating the urgency for employees to achieve high performance levels to attain desirable consequences and to avoid negative consequences (Mitchell et al., 2018).

Research on performance pressure has found that it is a unique and dynamic work stressor which acts as a double-edged sword in that it can motivate employees to perform well (Mitchell et al., 2019), be more ethical (Ness et al., 2017) and creative (Zhang et al., 2017), while also increasing stress (Mitchell et al., 2018) and deviant behavior (Jensen et al., 2019). Mitchell et al. (2019) theorized that performance pressure elicits both positive and negative workrelated behaviors which depends on the extent to which individuals appraise the performance pressure as a challenge or a threat. Challenge appraisal is defined as "an appraisal in which the perception of danger does not exceeds the perception of abilities or resources to cope with the stressor" (Tomaka et al., 1993, p. 248). In contrast, threat appraisal refers to "an appraisal in which the perception of danger exceeds the perception of abilities or resources to cope with the stressor" (Tomaka et al., 1993, p. 248). Individuals with challenge appraisals perceive the possibility of gain from meeting the assigned goals and are more likely to display positive behaviors (Ohly and Fritz, 2010). Whereas, individuals with threat appraisals perceive the potential for loss and possibility of failing to perform, thereby facilitating dysfunctional behaviors (Fugate et al., 2012). For example, students who think they are well-prepared are more likely to feel challenged, energized and eager to appear in the examination, whereas students who perceive themselves as unprepared are more likely to feel threatened and anxious to perform.

Performance pressure appraised as a threat can be detrimental (Mitchell et al., 2019). Employees' experiencing high demands for higher performance may perceive their efforts ineffective at meeting performance goals (Zhang et al., 2017). Employees appraising job demands (e.g. work pressure, performance pressure) as threatening may feel stress (Casper and Sonnentag, 2019) and may concentrate on the difficulties of raising performance and the adverse consequences that will likely result if performance demands are not met (Mitchell et al., 2019). These perceptions could also lead employees to experience negative outcomes such as job dissatisfaction (Quratulain and Khan, 2015), deviant behavior (Jensen et al., 2019; Soomro et al., 2020) and low job involvement (Sonnentag and Kruel, 2006) if performance is not raised. However, we lack empirical evidence on whether performance pressure impacts employee work engagement through threat appraisal. Based on Mitchell et al.'s (2019) theorization, performance pressure appraised as a threat depletes employees' self-resources (i.e. energy) which then leads to dysfunctional behavior. This depletion in self-resources may also lead employees to lower levels of work engagement (Xanthopoulou et al., 2009). Thus, on the basis of above theoretical principles and research findings, it can be presumed that threat appraisal emanating from performance pressure has a negative influence on employees' work engagement.

H1. Performance pressure has a negative indirect effect on work engagement through threat appraisal.

\section{Performance pressure, challenge appraisal and work engagement}

Performance pressure can also be appraised as a challenge (Mitchell et al., 2019). Demands for high level of performance can create a foundation for growth and development (Ab Wahab and Tatoglu, 2020). Ko and Choi (2019) argued that high demands for performance can 
promote performance, especially if workers perceived it as an opportunity for their career progression, growth or development. Moreover, employees may also view performance pressure as an opportunity to restructure their capabilities and focus on achieving the goals successfully (Gardner, 2012). In a meta-analysis, LePine et al. (2005) found a positive relation between challenge appraisal and performance and they argued that challenge appraisal facilitates performance through the direction, level and persistence of effort toward assigned tasks. They also argued that the appraisal of a situation as challenging should lead to the belief that if certain goals are met by exercising effort, valued outcomes will occur. Several studies clearly indicate that challenge appraisal is associated with various positive workrelated outcomes such as, creativity, performance, task proficiency and indicators of employee growth and development (Ko and Choi, 2019; Mitchell et al., 2019; Ohly and Fritz, 2010; Prem et al., 2017).

Existing research suggests that employees can cope well with a certain level of work pressure, which is expected to lead to more effort and thus increased work engagement (Leppinkand Pérez-Fuster, 2019; Petrou et al., 2017). Kronenwett and Rigotti (2020) argued that high work demand (in our case: high performance pressure) leads to an increase in effort because people try to meet their goals. This argument leads us to expect increased levels of work engagement when performance pressure is perceived as a challenge. According to Mitchel et al. (2019), employees who focus on attributes of performance pressure that are beneficial (i.e. challenge appraisal) fuel their internal self-resources (i.e. energy), which, in turn, enhances their engagement. Therefore, on the basis of Mitchel et al.'s (2019) theorization and research findings, it can be presumed that challenge appraisal emanating from performance pressure has a positive influence on employees' work engagement.

H2. Performance pressure has a positive indirect effect on work engagement through challenge appraisal.

\section{Moderating role of emotional stability}

The importance of personality traits for predicting work-related outcomes has been widely demonstrated (Albrecht and Marty, 2020; Alessandri et al., 2018; Tisuet al., 2020). Personality is often referred to as one's emotions, thoughts and behavioral patterns (Kassin, 2003). The Big five personality (also known as the Five-Factor Model) is frequently used to describe the structure of personality (Oentoro et al., 2016) and has been used in different countries, in various organizational settings and across rating sources. Although big five personality traits were derived since 1936 from the earlier trait research of Allport and Olbert (1936) and Cattell (1957), Tupes and Christal (1992) were the first to discover the Big Five-factor in 1961. The big five consists of five dimensions of personality, namely, conscientiousness, agreeableness, neuroticism, extraversion and openness to new experience. Emotional stability, the opposite of neuroticism, is one of the Big Five personality dimensions. Emotional stability, defined as an individual's capability to adequately cope with negative emotions, such as anxiety, stress and anger (Alessandri et al., 2018), has been considered as the basis of human personality. After conscientiousness, it is considered to be the most important personality trait in work contexts (Barrick and Mount, 2000) and a key individual characteristic that is negatively associated with stress-related variables, such as job burnout (Fornes-Vives et al., 2019), emotional exhaustion (Sosnowska et al., 2019), anxiety (Chen et al., 2020) and anger (Rogers and Barber, 2019).

According to Lazarus's (1966) transactional theory of stress, certain personality traits influence the stress process because they have the tendency to alter how individuals process information about stressors. Based on the arguments of Lazarus (1966), Mitchel et al. (2019) theorized that stress experience caused by the demand for high performance (i.e. performance pressure) can be influenced by certain personality traits in a way that could alter the way the 
pressure is appraised, which, in turn, could affect the performance pressure experience. Prior research on work-related stressors have identified emotional stability as a particular impactful individual trait for the stress process (Alessandri et al., 2018). Emotional stability captures individuals' predisposition to experience negative affect (Li and Ahlstrom, 2016) and helps individuals to stay calm under novel and stressful situations (Rogers and Barber, 2019). We focus on emotional stability as a potential moderator between performance pressure and stress appraisals (i.e. challenge or threat appraisals) because emotional stability captures the tendency for individuals to effectively adapt and cope with stress, loss, hardship or adversity (Alessandri et al., 2018; David et al., 2020). More important, accumulated research has established that emotional stability plays the most central role in shaping individuals' reactivity to stressors in terms of the effectiveness of coping strategies (Li et al., 2017) and navigating stress experiences positively rather than focusing on negative aspects of stressors (Kaiser and Ozer, 1997).

Accordingly, we suggest that emotional stability will moderate the effects of performance pressure on stress appraisals (i.e. threat and challenge appraisals). We further suggest that low emotional stability would decrease employee ability to ignore negative aspects of performance pressure, such as raising performance standards or meeting high performance demands, thus influencing employees to be more likely to appraise the performance pressure as threatening. In contrast, high emotional stability would enable greater employee ability to focus on the positive aspects of performance pressure (e.g. opportunities for growth and development or potential rewards against meeting the performance demands) and will help them navigate negative stress experience positively, thus making employees more likely to appraise the performance pressure as challenging. We thus hypothesize the following:

H3a. The positive relationship between performance pressure and threat appraisal will be stronger when emotional stability is lower rather than higher.

$H 3 b$. The positive relationship between performance pressure and challenge appraisal will be weaker when emotional stability is lower rather than higher.

Moreover, emotionally stability can increase employees' ability to remain stable and balanced and thus may optimize their personal resources (Albrecht and Marty, 2020) to secure themselves from hectic situations and its costs; furthermore, such personal resources act as a proximal antecedents of work engagement (Albrecht and Marty, 2020). Individuals with a higher level of emotional stability usually invest their energy to obtain more experience and increase work engagement (Janssens et al., 2019). By pre-empting the negative consequences of work pressure that may hinder performance, emotional stability help employees more effectively handle stressful situations(David et al., 2020; Smith et al., 2017) and thus enhance work engagement (Janssens et al., 2019). Therefore, we suggest that emotional stability switches the indirect effects of performance pressure between the appraisal and challenge pathways. That is, individuals with higher levels of emotional stability will perceive the performance pressure as a challenge rather than a threat because emotional stability trait helps individuals to stay calm under stressful situations (Alessandri et al., 2018), which would ultimately enhance their state of engagement (i.e. work engagement). Conversely, employees with lower levels of emotional stability will perceive the performance pressure as a threat rather than a challenge because they are often nervous, have low self-esteem and are unable to handle the stress effectively (Jankovic et al., 2021), which will ultimately affect their work engagement. Thus, we hypothesize following:

H4. The indirect effect of performance pressure on work engagement through (a) threat appraisal and (b) challenge appraisal will be stronger when emotional stability is higher. 


\section{Method}

\section{Participants and procedure}

Data were collected from white-collar employees working in different sectors in France, including those in the transport, banking, tourism, consulting and telecom sectors. These five sectors were targeted because they are the most common sectors in France. One of the authors personally contacted company managers in these sectors. Fifteen managers showed interest in our research project and invited employees working in their companies to join the research. We first informed the participants about the general aim of the study, how it would be carried out (i.e. in three waves) and provided assurances that their responses would be kept confidential. Due to the nature of our study (i.e. three-wave research design), we collected participants' email addresses and told them that they would receive the survey form by email. In addition, following the principles of snowball sampling (Biernacki and Waldorf, 1981), we asked the interested participants to recommend other participants. In addition, we sent invitations to French employees on professional networking sites such as LinkedIn and Viadeo. The inclusion criterion for the final sample was having a part- or full-time job in one of the five selected sectors.

To reduce common method bias (Podsakoff et al., 2012), the data collection occurred in three waves, separated by two months each. According to Luu (2019), a two-month time lag is sufficient to avoid the biasing effects of occasional factors (e.g. the pressure one faces at the time of survey completion). Matthews et al. (2014) also suggested that a minimum of onemonth time lag would be sufficient time for stressor-strain relationships to unfold. In the first phase, participants completed questionnaire regarding demographic variables, performance pressure and emotional stability. In the second phase, the survey measured mediating variables of threat appraisal and challenge appraisal. In the third phase, the participants were asked to complete work engagement scale. Initially, 625 participants completed the first survey. In the second wave, 353 respondents completed the survey and then 247 surveys were received in the third wave (overall response rate $=39 \%$ ).

The final sample included 138 women $(56 \%)$ and 109 men $(44 \%)$ employees with ages ranging from 20 to $54(M=30.8$ years, $\mathrm{SD}=6.8)$. On average, respondents had a mean tenure of 5.7 years $(\mathrm{SD}=2.17)$. The majority of the participants were employed in the private sector $(68 \%)$ and represented each of the five sectors, i.e. banking (30\%), consulting (28\%), telecom $(18 \%)$, transportation (13\%) and tourism (11\%). Of the respondents, $90.7 \%$ had a bachelor's degree and $36.8 \%$ worked in the managerial positions.

\section{Measures}

The survey was administered both in English and French since these languages are spoken by a vast majority of French population and are commonly used in organizational contexts (Kundi et al., 2020). We followed the back-translation procedure recommended by Brislin (1980) to translate the scales from English to French.

Performance pressure. Performance pressure was measured with a four-item scale developed by Mitchell et al. (2018). Sample items are "I feel tremendous pressure to produce results" and "I feel that if I do not produce at high levels, my job will be at risk" $(\alpha=0.82)$. Items were rated on a 7-point scale $(1=$ strongly disagree and $7=$ strongly agree).

Threat appraisal. We measured threat appraisal with three items borrowed from DrachZahavy and Erez (2002). Sample items are "The demands of my work hinder my abilities "and" I'm worried that the task might reveal my weaknesses" $(\alpha=0.97)$. Items were rated on a 7 -point scale $(1=$ strongly disagree and $7=$ strongly agree).

Challenge appraisal. Challenge appraisal was measured using three items from DrachZahavy and Erez (2002). Sample items are "The task seems like a challenge to me" and "The task provides opportunities to exercise reasoning skills" ( $\alpha=0.91)$. Items were rated on a 7 -point scale ( 1 = strongly disagree and 7 = strongly agree). 
Work engagement. Work engagement was measured with three items borrowed from the Ultrecht Work Engagement Scale (UWES; Schaufeli et al., 2002), also used by Wang et al. (2020). According to Schaufeli et al. (2002), work engagement has three dimensions, i.e. vigor, absorption and dedication, which tend to correlate significantly with each other and usually load together. The three items for work engagement are "I feel bursting with energy at work", "I am enthusiastic about my work" and "I am immersed in my work" $(\alpha=0.86)$. Items were rated on a 7 -point scale $(1=$ not at all and $7=$ extremely $)$.

Emotional stability. Emotional stability was measured with a ten-item negative affectivity scale (Watson et al., 1988). Negative affectivity is characterized by experiencing negative emotions (Watson and Clark, 1984). All the items of negative affectivity scale were reversed coded to measure emotional stability since these two constructs are often used interchangeably (see Wihler et al., 2017). The instructions read "To what extent do you feel this way generally." A sample item includes "nervous". Items were rated on a 7- point scale $(1=$ not at all and $7=$ extremely). Cronbach's $\alpha=0.85$.

Control variables. In our analysis, we controlled for age, gender and organizational tenure as these factors have been found to influence employee work engagement (e.g. Bakker et al., 2005; Matsuo, 2019).

\section{Results}

Descriptive statistics

Table 1 presents the means, standard deviations and bivariate correlations among the study variables.

\section{Measurement assessment}

Prior to hypotheses testing, we used confirmatory factor analysis (CFA) to examine the distinctiveness of the five variables included in this study, namely, performance pressure, threat appraisal, challenge appraisal, emotional stability and work engagement. Comparing the baseline model against several alternative models revealed that the five-factor model was statistically significant above and beyond alternate models $\left(\chi^{2}=247.931\right.$, df $=123$, $\mathrm{CFI}=0.96$, TLI $=0.95, \mathrm{RMSEA}=0.06$, and SRMR $=0.05$; see Table 2 ). These results provide empirical support for the distinctive nature of our study variables and meet the standard cutoff values proposed by Hu and Bentler (1999). To ensure the validity of our measures, we first examined the convergent validity through: (1) construct reliability (i.e. composite reliability) and (2) average variance extracted (AVE). We found composite reliability coefficients higher than the threshold value of 0.7 , whereas AVE scores higher than the threshold value of 0.5 (see Table 1; Fornell and Larcker 1981), supporting the convergent validity of our constructs. We also estimated discriminant validity by comparing the AVE of each construct with the average shared variance (ASV), i.e. mean of the squared correlations among constructs (Hair et al., 2010). As expected, all the values of AVE were higher than the ASV constructs, thereby supporting discriminant validity (see Table 1).

Finally, we tested for the presence of a common method effect since we collected data from the same source (i.e. employees).We ran a CFA version of Harman's single-factor test (cf. Kundi et al., 2020a, b). The results showed that the single-factor model produced an extremely poor fit to the data $\chi^{2}=1789.28$, df $=133$, CFI $=0.43$, TLI $=0.34$, RMSEA $=0.23$, SRMR $=0.24$ ). In addition, we conducted CFA marker variable technique (Lindell and Whitney, 2001; Williams et al., 2010) to assess CMV. We used De Witte's (2000) four-item job insecurity scale (e.g. "I feel insecure about the future of my job") as a marker variable. We ran a model in which the indicators of the study's substantive variables were specified to load onto the latent marker variable $\left.\chi^{2}=296.797, \mathrm{df}=171\right)$ and compared it to a model in which 


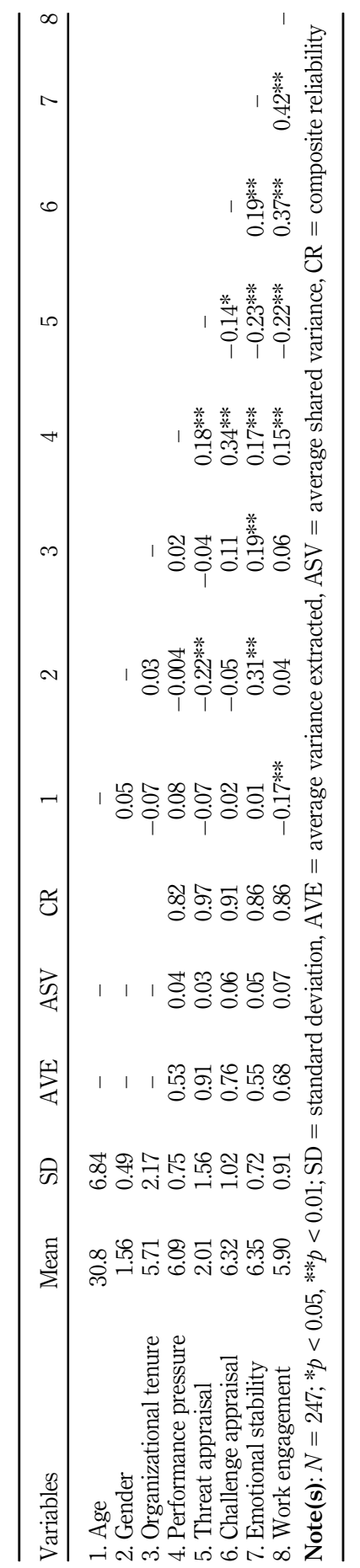

Table 1. Correlations and descriptive analysis 
they did not load onto the marker variable $\left(\chi^{2}=243.699, \mathrm{df}=122\right)$. The chi-square difference test between two models was nonsignificant $\left(\Delta \chi^{2}=53.098, \Delta \mathrm{df}=49, p=0.32\right)$, suggesting that CMV is not a pervasive problem.

\section{Hypotheses testing}

The hypotheses pertaining to mediation were tested using a structural model (see Figure 2), which had an acceptable goodness of fit, i.e. $\chi^{2}(58)=114.649$, CFI $=0.98$, TLI $=0.97$, RMSEA $=0.06$, and SRMR $=0.04$. Hypotheses pertaining to moderation and moderated mediation were tested in SPSS (25th edition) using PROCESS model 7 (Hayes, 2017; see Table 3). Studies that theorized and tested moderated mediation research models increasingly relied on this approach (e.g. De Clercq et al., 2021; Matsuo, 2019).

Hypothesis 1 suggested that performance pressure has a negative indirect effect on work engagement via threat appraisal. As shown in Figure 2, the indirect effect of performance pressure on work engagement, through threat appraisal, was negative and significant $(\beta=-0.042,95 \% \mathrm{CI}=-0.103 ;-0.001)$, supporting Hypothesis 1 . Similarly, Hypothesis 2 suggested that performance pressure has a positive indirect effect on work engagement via challenge appraisal. As shown in Figure 2, the indirect effect of performance pressure on work engagement, through challenge appraisal, was positive and significant $(\beta=0.128,95 \%$ $\mathrm{CI}=0.128 ; 0.489)$, supporting Hypothesis 2.

Table 2.

Results of confirmatory factor analysis

\begin{tabular}{lccccccc}
\hline Model & $x^{2}$ & df & $\Delta x^{2}$ & CFI & TLI & RMSEA & SRMR \\
\hline Model I (hypothesized five-factor model) & 247.93 & 123 & - & 0.96 & 0.95 & 0.06 & 0.05 \\
Model II (four-factor model: combines PP and & 546.93 & 128 & $298^{* *}$ & 0.85 & 0.82 & 0.12 & 0.13 \\
ES) & & & & & & & \\
Model III (four-factor model: combines threat & 787.47 & 127 & $539.5^{* *}$ & 0.77 & 0.72 & 0.15 & 0.15 \\
$\begin{array}{l}\text { and challenge appraisals) } \\
\text { Model IV (one-factor model) }\end{array}$ & 1789.28 & 133 & $1541.4^{* *}$ & 0.43 & 0.34 & 0.23 & 0.24
\end{tabular}

Note(s): ${ }^{*} p<0.05, * * p<0.01$; PP $=$ performance pressure, ES $=$ emotional stability; $x^{2}=$ chi-square, $\mathrm{df}=$ degree of freedom, RMSEA $=$ Root mean square error of approximation, $\mathrm{CFI}=$ comparative fit index, $\mathrm{TLI}=$ Tucker-Lewis index, SRMR $=$ Standardized root mean square residual

Figure 2.

The results of structural model with standardized coefficients. $N=247$; dotted lines represent direct path; are estimated; $* p<0.05, * * p<0.01$

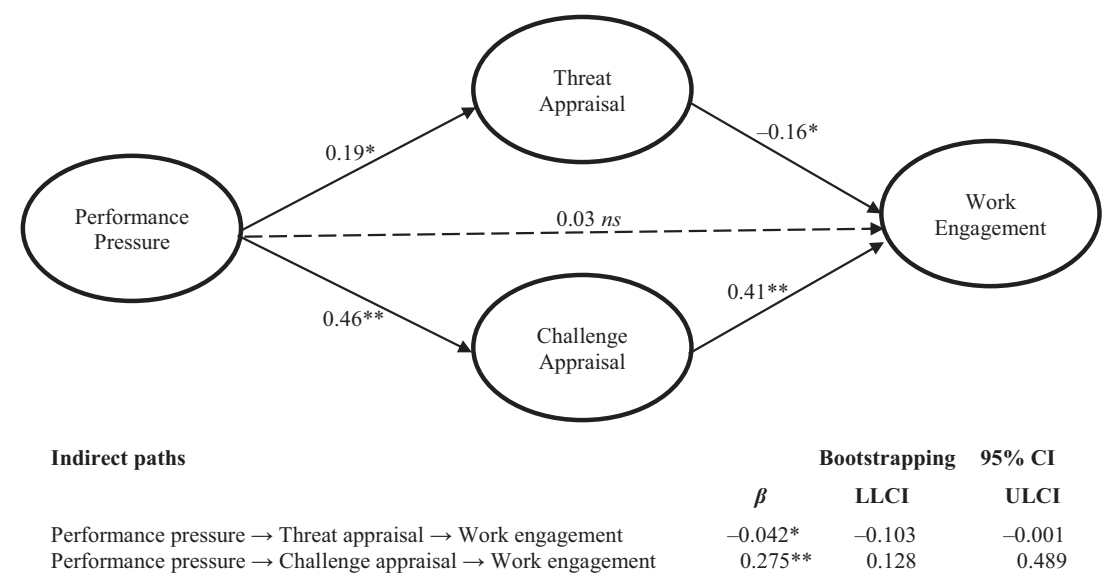




\begin{tabular}{lcccc}
\hline & \multicolumn{2}{c}{ Treat appraisal } & \multicolumn{2}{c}{ Challenge appraisal } \\
& $\beta$ & SE & $\beta$ & SE \\
\hline Performance pressure & $0.46^{* * *}$ & 0.13 & $0.43^{* *}$ & 0.08 \\
Emotional stability & $-0.68^{* *}$ & 0.14 & $0.30^{* *}$ & 0.08 \\
Emotional stability $\times$ Performance pressure & $-0.42^{*}$ & 0.16 & $0.31^{* *}$ & 0.09 \\
Conditional indirect effect and index of moderation-mediation & & & \\
\hline
\end{tabular}

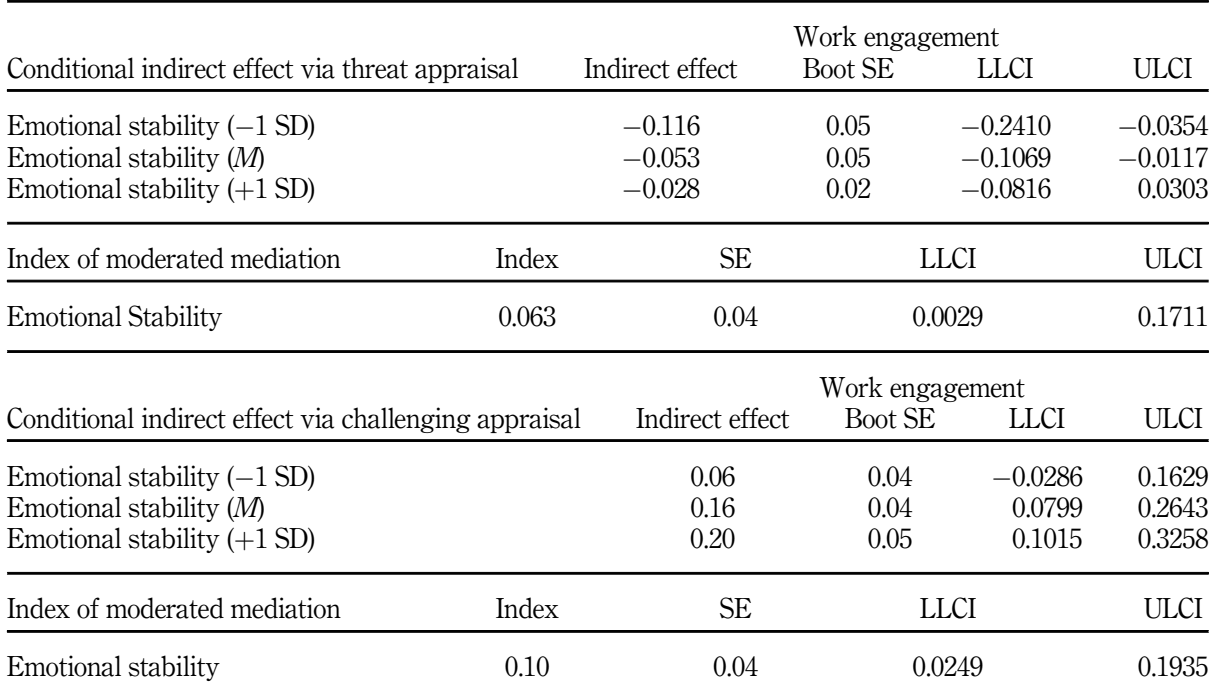

Note(s): $* p<0.1, * * p<0.05$; Unstandardized coefficients and average bootstrap estimates are stated; bootstrapping procedure [5,000 iterations, bias-corrected, 95\% CI]; Sample size $=247$

Table 3. Results of moderation and moderatedmediation (PROCESS, model 7)

Hypothesis 3a suggested that the positive effect of performance pressure on threat appraisal will be stronger when emotional stability was lower than higher. As can be seen in Table 3, the interaction term between performance pressure and emotional stability negatively influenced threat appraisal $(\beta=-0.42, p<0.05)$. In order to interpret the interaction effects, the simple slopes for the significant interaction effects (i.e. for the low and high values of the moderating variables) were plotted (see Figure 3) and assessed for significance. Simple slope test results revealed that the linkage between performance pressure and threat appraisal was significant when emotional stability was low $(-1 \mathrm{SD}, \beta=0.76, p<0.001)$ rather than high $(+1$ $\mathrm{SD}, \beta=0.18, n s)$. Hypothesis 3a, therefore, was fully supported.

Hypothesis $3 \mathrm{~b}$ suggested that the positive effect of performance pressure on challenge appraisal will be stronger when emotional stability was higher than lower. As can be seen in Table 3 , the interaction term between performance pressure and emotional stability positively influenced challenge appraisal $(\beta=0.31, p<0.01)$. The plot is presented in Figure 4 . As expected, performance pressure was positively related to challenge appraisal when emotional stability was high $(+1 \mathrm{SD}, \beta=0.63, p<0.001)$ rather than low $(-1 \mathrm{SD}, \beta=0.19, n s)$. Hence, Hypothesis 3b was fully supported.

Hypothesis 4 suggested that the indirect effects of performance pressure on work engagement through (1) threat appraisal and (2) challenge appraisal will be stronger when emotional stability is higher than lower. The results showed that the indirect effect of performance pressure on work engagement through threat appraisal was stronger when emotional stability was higher $(\beta=-0.028,95 \% \mathrm{CI}=-0.0816 ; 0.0303)$ rather than lower 
$(\beta=-0.117,95 \% \mathrm{CI}=-0.2410 ;-0.0354)$. The index of moderated mediation was significant (Index $=0.063,95 \%$ CI $=0.0029 ; 0.1711$ ). Similarly, the indirect effect of performance pressure on work engagement through challenge appraisal was stronger when emotional stability was higher $(\beta=0.20,95 \% \mathrm{CI}=0.1015 ; 0.3258)$ rather than lower $(\beta=0.06,95 \%$ $\mathrm{CI}=-0.0286 ; 0.1629)$. The index of moderated mediation was significant (Index $=0.10,95 \%$ $\mathrm{CI}=0.0249 ; 0.1935)$. Overall, these results supported Hypothesis $4 \mathrm{a}$ and $4 \mathrm{~b}$.

\section{Discussion}

The purpose of this research was to uncover the relationship between performance pressure and employee work engagement. Integrating Lazare's theory of stress (1966) with the tenets of Mitchell et al.'s (2019) theorization, we hypothesized that performance pressure would yield both positive and negative consequences on employee work engagement. We found that performance pressure experience has both positive and negative outcomes. When performance pressure is perceived as a threat, it creates a taxing experience that lowers employee work engagement. In contrast, when the performance pressure is perceived as a challenge or opportunity, it promotes employee work engagement. Furthermore, we found emotional stability as an influential personality trait in this stress experience because it creates a lens through which employee filter the performance pressure. We found that employees with low emotional stability are more likely to appraise the performance pressure as threatening, thereby diminishing their work engagement, whereas employees with high

\section{Figure 3.}

The moderating role of emotional stability on performance pressurethreat appraisal relationship
Figure 4.

The moderating role of emotional stability on performance pressurechallenge appraisal relationship
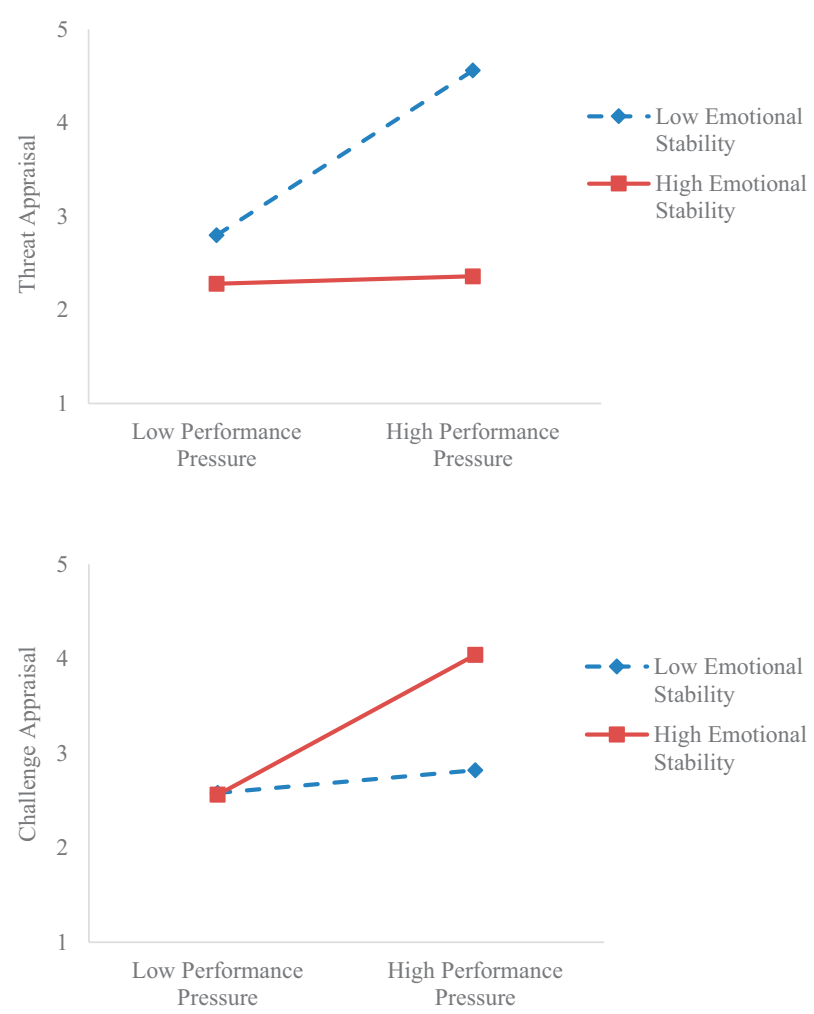
levels of emotional stability are more likely to appraise the performance pressure as challenging, thereby enhancing their work engagement.

\section{Theoretical implications}

Our study has several theoretical implications. First, our study contributes to and advances the emerging literature on performance pressure, which has previously produced mixed results on outcomes of such pressure. Some research demonstrated that performance pressure enhances functional behavior (e.g. Tan et al., 2017; Zhang et al., 2017), while others found performance pressure producing dysfunctional behavior (e.g. Byun et al., 2020; Jensen et al., 2019), and some even reported both positive and negative outcomes (Mitchell et al., 2019). Based on tenets of Mitchell et al.'s (2019) theory, our primary contribution lies in investigating the paradoxical consequences of performance pressure on employee work engagement. Although it has been argued that performance pressure is appraised as either threat or challenge (Mitchell et al., 2019), which in turn may leads to both positive and negative consequences (Baethge et al., 2018), research explicitly investigating the consequences of such pressure on employee work engagement has largely been absent from the extant literature. Our results showed that performance pressure has both positive and negative consequences. Surprisingly, we found a positive indirect relationship between performance pressure and employee work engagement when the pressure was appraised as a challenge and an indirect negative relationship between performance pressure and work engagement when the pressure was appraised as a threat. The findings support Mitchell et al.'s (2019) theory which implies that performance pressure is a double-edge sword, either appraised as a threat or as a challenge. If appraised as a challenge, it may have positive outcomes, and if appraised as a threat, it may have negative outcomes. This finding presents the study's first theoretical contribution to the work engagement literature by providing evidence of the existence paradoxical outcomes between perceived performance pressure and work engagement. Namely, to date, only one study has investigated the relationship between performance pressure and engagement but only through the path of challenge appraisal (Mitchell et al., 2019).

Second, we contribute to the personality literature by examining the moderating role of emotional stability targeted at the two types of appraisals, i.e. threat and challenge appraisals. We responded to Mitchell et al.'s (2019) call to examine the moderating role of different personality traits, especially emotional stability, on the stress process triggered by the performance pressure. We found that emotional stability strengthens the effects of performance pressure on challenge appraisal, whereas emotional stability mitigates the effects of performance pressure on threat appraisal. These results suggest that performance pressure benefits can be mixed for organizations unless employees have high emotional stability because emotional stability offers an optimistic lens through which employees appraise the pressure as beneficial and challenging rather than harmful or threatening. Rogers and Barber (2019) argued that emotional stability is characterized by stress tolerance and decreased negative affect. They also argued that emotional stability serves as a personal resource, such that emotionally stable employees may perceive fewer work pressures and experience less stress as a result of such pressures. Previous studies have found that employees scoring high on emotional stability are more likely to engage in response to stressors (Alessandri et al., 2018; David et al., 2020; Fornes-Vives et al., 2019; Sosnowska et al., 2019).

Moreover, we contribute to the work engagement literature by examining how a single stressor (i.e. performance pressure) can motivate different reactions (i.e. threat and challenge appraisals), ultimately influencing employees' work engagement. We draw on Lazarus's (1966) theory of stress with the tenets of Mitchell et al.'s (2019) theory to examine the moderating role of emotional stability on the performance pressure and work engagement relationship. Our results indicated that employees with high emotional stability are more likely to appraise the pressure as beneficial and challenging rather than harmful and 
threatening, which promotes their work engagement. Employees with high emotional stability are more likely to experience positive emotions (Li and Ahlstrom, 2016) rather than a range of negative emotions such as depression, anxiety and stress than those with low emotional stability (Alessandri et al., 2018; David et al., 2020). In addition, employees with high emotional stability have strong desires to attain success and achieve high performance (Wihler et al., 2017) and, thus, develop a stronger sense of obligation to put efforts toward job (Kleine et al., 2019). As such, we demonstrated that employee stability could be both functional (when high) and dysfunctional (when low) in perceiving performance pressure. In doing so, we enrich the knowledge of the effects of performance pressure and emotional stability by identifying individuals who are more likely to be influenced by performance pressure.

\section{Practical implications}

Performance pressure at work is increasing (Jensen et al., 2019), and there are no indicators of a trend in the opposite direction; therefore, managers are confronted with the challenge of how to motivate an employee to perform well, one of the most desirable behaviors in today's work environment (Prouska et al., 2016). Our study investigates this challenge, and the results offer some practical implications. First, findings suggest that performance pressure can be a double-edged sword, motivating both positive and negative outcomes. Employees appraising the performance pressure as a threat may be motivated toward dysfunctional behavior. However, employees appraising it as a challenge may increase functional behavior at work. Therefore, managers should be aware of how their employees appraise performance expectations. Managers should take care in how they communicate performance expectations to employees to diminish the likelihood that those expectations may be negatively appraised (i.e. threat appraisal). Instead, managers should be able to facilitate increased employee motivation by explaining the benefits and opportunities tied with meeting those expectations.

Second, our study proposed that performance pressure could be favorable to work engagement. Thus, if supervisors are interested in boosting employees' work engagement, they should identify how they appraise the pressure. If the pressure is appraised as a challenge, it may boost their energy (Ohly and Fritz, 2010; Prem et al., 2017) ultimately enhancing their work engagement. However, if the pressure is appraised as a threat, employees may lose hope and feel demotivated (Mitchell et al., 2018) ultimately lowering their work engagement. It is important to note that frequent and continuous high-performance pressure may lead to incivility and other negative consequences (Mitchell et al., 2019). Thus, it is important that managers with higher performance expectations should provide employees with full support to stimulate their work engagement. Besides this, managers need to ensure that long-term exposure to high-performance pressure should be avoided (Baethge et al., 2018).

Finally, our findings suggest that performance pressure may be both harmful and helpful; however, it depends on the person experiencing the performance pressure. We found that employees with high emotional stability paid attention to challenging aspects of performance pressure while seemingly ignoring threatening aspects of the pressure. They were found to have greater work engagement due to performance pressure. On the other hand, employees with low emotional stability were more likely to appraise performance pressure as threatening, ultimately lowering their work engagement. Therefore, organizations should use personality measures to assess important personality traits during hiring and screening processes because certain traits influence positive motivational states and behaviors (ZeiglerHill et al., 2019). Moreover, managers could choose employees with high emotional stability for the tasks that require high work demand and are challenging in nature. Last but not least, interventions such as enhancing employees' levels of mindfulness, creating resourceful work environment (e.g. redesigning jobs and providing social support), and provision of training, 
counseling and mentoring can prove to be effective in enhancing employees' emotional stability (Bakker and Demerouti, 2017; Bajaj et al., 2019).

\section{Limitations and future research directions}

There are several limitations to this study. First, all variables in our study were assessed with self-report scales which may raise concerns about common method bias (Podsakoff et al., 2012). Yet, collecting sensitive behaviors from the focal source has been demonstrated by meta-analysis to be more accurate than reports from others (Carpenter et al., 2017). We addressed the possibility of CMV in our surveys by (1) using three-wave data collection procedure, (2) conducting CFA marker variable analyses which suggested that common method bias was unlikely to be a problem and (3) included a moderator variable in our model which scholars have demonstrated cannot be inflated by CMV (e.g. Podsakoff et al., 2012; Siemsen et al., 2010). We found significant interaction effects of emotional stability, and the indirect effect of performance pressure on work engagement (through threat and challenge appraisals) was also significant. Therefore, it is unlikely CMV presented a bias and, based on Podsakoff et al.'s (2012) arguments, if CMV were present, the interactions would have been deflated by CMV. However, future research should attempt to replicate our results by using alternative research designs, such as experimental or longitudinal studies, that strengthen assumptions of causality and mitigate common method bias.

Second limitation concerns generalizing our study's findings to other cultures and regions as the sample is exclusively from France. Future research may benefit from examining our model within other relevant contexts across a range of countries and cultures. Third, although we have involved age, gender and organizational tenure as the control variables, other factors may influence work engagement. For instance, previous research has shown that work engagement is highly determined by job resources (Bakker and Demerouti, 2017), which longitudinally show reciprocal relationships with personal resources and work engagement (Xanthopoulou et al., 2009). Thus, future research, when attempting to replicate our study's results, consider additional control variables.

Finally, our study has highlighted an important role of emotional stability on weakening the negative effects (i.e. threat appraisal) of performance pressure. Future research can explore the effect of other personality traits (e.g. promotion-focused, perfectionism and proactive personality) which may enhance or dull the salience of stressors. Future research might also explore the moderating role of contextual factors (e.g. instrumental, personal or supervisor support received at work) with respect to our model.

\section{Conclusion}

Our study has shown that performance pressure can have differential effects on employees' work engagement. Performance pressure appraised as a threat diminishes employees' work engagement, whereas performance pressure appraised as a challenge promotes employees' work engagement. Emotional stability influences the performance pressure stress experience such that higher emotional stability enhances employee ability to handle the pressure due to being more likely to view it as challenge, which heightens engagement behaviors at work. Finally, we want to add and emphasize that research on performance pressure has documented its health-impairing effects (Mitchell et al., 2018). Because previous evidence indicates that stress arising from high work demands tends to increase over time (De Lange et al., 2009), practitioners should keep the potential for both the beneficial and healthimpairing effects of performance pressure in mind. Keeping an eye on contextual features, as well as the availability of resources, will become increasingly important for organizations to maintain a high performing and engaging workforce in turbulent economic times. 


\section{References}

Ab Wahab, M. and Tatoglu, E. (2020), "Chasing productivity demands, worker well-being, and firm performance: the moderating effects of HR support and flexible work arrangements", Personnel Review, Vol. 49 No. 9, pp. 1823-1843.

Aboramadan, M. and Kundi, Y.M. (2020), "Does transformational leadership better predict workrelated outcomes than transactional leadership in the NPO context? Evidence from Italy", Voluntas: International Journal of Voluntary and Nonprofit Organizations, Vol. 31 No. 6, pp. 1254-1267.

Albrecht, S.L. and Marty, A. (2020), "Personality, self-efficacy and job resources and their associations with employee engagement, affective commitment and turnover intentions", International Journal of Human Resource Management, Vol. 31 No. 5, pp. 657-681.

Alessandri, G., Perinelli, E., De Longis, E., Schaufeli, W.B., Theodorou, A., Borgogni, L. and Cinque, L. (2018), "Job burnout: the contribution of emotional stability and emotional self efficacy beliefs", Journal of Occupational and Organizational Psychology, Vol. 91 No. 4, pp. 823-851.

Allport, G.W. and Odbert, H.S. (1936), "Trait-names: a psycho-lexical study", Psychological Monographs, Vol. 47 No. 1, pp. 1-171.

Baethge, A., Vahle-Hinz, T., Schulte-Braucks, J. and van Dick, R. (2018), "A matter of time? Challenging and hindering effects of time pressure on work engagement", Work and Stress, Vol. 32 No. 3, pp. 228-247.

Bajaj, B., Gupta, R. and Sengupta, S. (2019), "Emotional stability and self-esteem as mediators between mindfulness and happiness", Journal of Happiness Studies, Vol. 20 No. 7, pp. 2211-2226.

Bakker, A.B. and Demerouti, E. (2017), "Job demands-resources theory: taking stock and looking forward", Journal of Occupational Health Psychology, Vol. 22 No. 3, pp. 273-285.

Bakker, A.B., Demerouti, E. and Schaufeli, W.B. (2005), "The crossover of burnout and work engagement among working couples”, Human Relations, Vol. 58 No. 5, pp. 661-689.

Barrick, M.R. and Mount, M.K. (2000), "Select on conscientiousness and emotional stability", in Locke, E.A. (Ed.), Handbook of Organizational Behavior, Blackwell, Malden, MA, pp. 13-29.

Baucus, M.S. (1994), "Pressure, opportunity and predisposition: a multivariate model of corporate illegality”, Journal of Management, Vol. 20 No. 4, pp. 699-721.

Baumeister, R.F. (1984), "Choking under pressure: self-consciousness and paradoxical effects of incentives on skillful performance", Journal of Personality and Social Psychology, Vol. 46 No. 3, p. 610 .

Biernacki, P. and Waldorf, D. (1981), "Snowball sampling: problems and techniques of chain referral sampling”, Sociological Methods and Research, Vol. 10 No. 2, pp. 141-163.

Brislin, R.W. (1980), "Translation and content analysis of oral and written materials", Methodology, pp. 389-444.

Byun, G., Lee, S., Karau, S.J. and Dai, Y. (2020), "The trickle-down effect of empowering leadership: a boundary condition of performance pressure", Leadership and Organization Development Journal, Vol. 41 No. 3, pp. 399-414.

Carpenter, N.C., Rangel, B., Jeon, G. and Cottrell, J. (2017), "Are supervisors and coworkers likely to witness employee counterproductive work behavior? An investigation of observability and self-observer convergence", Personnel Psychology, Vol. 70 No. 4, pp. 843-889.

Casper, A. and Sonnentag, S. (2019), "Feeling exhausted or vigorous in anticipation of high workload? The role of worry and planning during the evening", Journal of Occupational and Organizational Psychology, Vol. 93 No. 1, pp. 215-242.

Cattell, R.E. (1957), Personality and Motivation Structure and Measurement, World Book, New York, NY.

Cavanaugh, M.A., Boswell, W.R., Roehling, M.V. and Boudreau, J.W. (1998), "Challenge and hindrance related stress among U.S. managers”, Journal of Applied Psychology, Vol. 85, pp. 65-74. 
Cavanaugh, M.A., Boswell, W.R., Roehling, M.V. and Boudreau, J.W. (2000), "An empirical examination of self-reported work stress among US managers", Journal of Applied Psychology, Vol. 85, pp. 65-74.

Chen, X., Pu, J., Shi, W. and Zhou, Y. (2020), "The impact of neuroticism on symptoms of anxiety and depression in elderly adults: the mediating role of rumination", Current Psychology, Vol. 39 No. 1, pp. 42-50.

David, E.M., Shoss, M.K., Johnson, L.U. and Witt, L.A. (2020), "Emotions running high: examining the effects of supervisor and subordinate emotional stability on emotional exhaustion", Journal of Research in Personality, Vol. 84, 103885.

De Clercq, D., Kundi, Y.M., Sardar, S. and Shahid, S. (2021), "Perceived organizational injustice and counterproductive work behaviours: mediated by organizational identification, moderated by discretionary human resource practices", Personnel Review.

De Lange, A.H., Kompier, M.A., Taris, T.W., Geurts, S.A., Beckers, D.G., Houtman, I.L. and Bongers, P.M. (2009), “A hard day's night: a longitudinal study on the relationships among job demands and job control, sleep quality and fatigue", Journal of Sleep Research, Vol. 18 No. 3, pp. 374-383.

De Witte, H. (2000), “Arbeidsethos en jobonzekerheid: meting en gevolgen voor welzijn, tevredenheid en inzet op het werk", in Bouwen, R., De Witte, K., De Witte, H. and Taillieu, T. (Eds), Van groep naar gemeenschap. Liber Amicorum Prof. Dr. Leo Lagrou, Garant, Leuven, pp. 325-350.

Drach-Zahavy, A. and Erez, M. (2002), "Challenge versus threat effects on the goal-performance relationship", Organizational Behavior and Human Decision Processes, Vol. 88 No. 2, pp. 667-682.

Eisenberger, R. and Aselage, J. (2009), "Incremental effects of reward on experienced performance pressure: positive outcomes for intrinsic interest and creativity", Journal of Organizational Behavior, Vol. 30 No. 1, pp. 95-117.

Fornell, C. and Larcker, D.F. (1981), "Structural equation models with unobservable variables and measurement error: algebra and statistics", Journal of Marketing Research, Vol. 18 No. 3, pp. 382-388.

Fornes-Vives, J., García-Banda, G., Frias-Navarro, D. and Pascual-Soler, M. (2019), "Longitudinal study predicting burnout in Spanish nurses: the role of neuroticism and emotional coping", Personality and Individual Differences, Vol. 138, pp. 286-291.

Fugate, M., Prussia, G.E. and Kinicki, A.J. (2012), "Managing employee withdrawal during organizational change: the role of threat appraisal", Journal of Management, Vol. 38 No. 3 , pp. 890-914.

Gardner, H.K. (2012), "Performance pressure as a double-edged sword: enhancing team motivation but undermining the use of team knowledge", Administrative Science Quarterly, Vol. 57 No. 1, pp. 1-46.

Hair, J.F., Black, W.C., Babin, B.J. and Anderson, R.E. (2010), Multivariate Data Analysis: A Global Perspective, 7th ed., Pearson, Boston, Massachusetts, MA.

Hayes, A.F. (2017), Introduction to Mediation, Moderation, and Conditional Process Analysis: A Regression-Based Approach, Guilford publications, New York, NY.

$\mathrm{Hu}$, L.T. and Bentler, P.M. (1999), “'Cutoff criteria for fit indexes in covariance structure analysis: conventional criteria versus new alternatives", Structural Equation Modeling: A Multidisciplinary Journal, Vol. 6 No. 1, pp. 1-55.

Jankovic, M., Sijtsema, J.J., Reitz, A.K., Masthoff, E.D. and Bogaerts, S. (2021), "Workplace violence, post-traumatic stress disorder symptoms, and personality", Personality and Individual Differences, Vol. 168, 110410.

Janssens, H., De Zutter, P., Geens, T., Vogt, G. and Braeckman, L. (2019), "Do personality traits determine work engagement? Results from a Belgian study", Journal of Occupational and Environmental Medicine, Vol. 61 No. 1, pp. 29-34. 
Jensen, J.M., Cole, M.S. and Rubin, R.S. (2019), "Predicting retail shrink from performance pressure, ethical leader behavior, and store-level incivility", Journal of Organizational Behavior, Vol. 40 No. 6, pp. 723-739.

Kaiser, R.T. and Ozer, D.J. (1997), "Emotional stability and goal-related stress", Personality and Individual Differences, Vol. 22 No. 3, pp. 371-379.

Kassin, S. (2003), Psychology, Prentice-Hall, Upper Saddle River, New Jersey, NJ.

Kleine, A.K., Rudolph, C.W. and Zacher, H. (2019), "Thriving at work: a meta-analysis”, Journal of Organizational Behavior, Vol. 40 Nos 9-10, pp. 973-999.

Ko, Y.J. and Choi, J.N. (2019), "Overtime work as the antecedent of employee satisfaction, firm productivity, and innovation”, Journal of Organizational Behavior, Vol. 40 No. 3, pp. 282-295.

Kronenwett, M. and Rigotti, T. (2020), "All's well that ends well!? Moderating effects of goal progress on the relation between challenge and hindrance appraisal and well-being", Journal of Managerial Psychology.

Kundi, Y.M., Aboramadan, M., Elhamalawi, E.M.I. and Shahid, S. (2020a), "Employee psychological well-being and job performance: exploring mediating and moderating mechanisms", International Journal of Organizational Analysis.

Kundi, Y.M., Hollet-Haudebert, S. and Peterson, J. (2020b), "Linking protean and boundaryless career attitudes to subjective career success: a serial mediation model", Journal of Career Assessment.

Lazarus, R.S. (1966), Psychological Stress and the Coping Process, McGraw Hill, New York, NY.

Lazarus, R.S. and Folkman, S. (1984), Stress, Appraisal, and Coping, Springer, New York, NY.

LePine, J.A., Podsakoff, N.P. and LePine, M.A. (2005), "A meta-analytic test of the challenge stressorhindrance stressor framework: an explanation for inconsistent relationships among stressors and performance", Academy of Management Journal, Vol. 48 No. 5, pp. 764-775.

Leppink, J. and Pérez-Fuster, P. (2019), "Mental effort, workload, time on task, and certainty: beyond linear models", Educational Psychology Review, Vol. 31, pp. 421-438.

Li, Y. and Ahlstrom, D. (2016), "Emotional stability: a new construct and its implications for individual behavior in organizations", Asia Pacific Journal of Management, Vol. 33 No. 1, pp. 1-28.

Li, J.J., Burch, T.C. and Lee, T.W. (2017), "Intra-individual variability in job complexity over time: examining the effect of job complexity trajectory on employee job strain: job Complexity Change and Job Strain”, Journal of Organizational Behavior, Vol. 38 No. 5, pp. 671-691.

Lindell, M.K. and Whitney, D.J. (2001), "Accounting for common method variance in cross-sectional research designs", Journal of Applied Psychology, Vol. 86 No. 1, p. 114.

Liu, X. and Yu, K. (2019), "Emotional stability and citizenship fatigue: the role of emotional exhaustion and job stressors", Personality and Individual Differences, Vol. 139, pp. 254-262.

Luu, T.T. (2019), "Discretionary HR practices and employee well-being”, Personnel Review, Vol. 49 No. 1, pp. 43-66.

Matsuo, M. (2019), "Effect of learning goal orientation on work engagement through job crafting: a moderated mediation approach", Personnel Review, Vol. 48 No. 1, pp. 220-233.

Matthews, R.A., Winkel, D.E. and Wayne, J.H. (2014), “A longitudinal examination of role overload and work-family conflict: the mediating role of interdomain transitions: interdomain transitions", Journal of Organizational Behavior, Vol. 35 No. 1, pp. 72-91.

Mitchell, M.S., Baer, M.D., Ambrose, M.L., Folger, R. and Palmer, N.F. (2018), "Cheating under pressure: a self-protection model of workplace cheating behavior", Journal of Applied Psychology, Vol. 103 No. 1, p. 54.

Mitchell, M.S., Greenbaum, R.L., Vogel, R.M., Mawritz, M.B. and Keating, D.J. (2019), “Can you handle the pressure? The effect of performance pressure on stress appraisals, self-regulation, and behavior", Academy of Management Journal, Vol. 62 No. 2, pp. 531-552. 
Ness, A.M. and Connelly, S. (2017), "Situational influences on ethical sense making: performance pressure, interpersonal conflict, and the recipient of consequences", Human Performance, Vol. 30 Nos 2-3, pp. 57-78.

Oentoro, W., Popaitoon, P. and Kongchan, A. (2016), "Perceived supervisory support and service recovery performance: the moderating role of personality traits", Asia-Pacific Journal of Business Administration, Vol. 8 No. 3, pp. 298-316.

Ohly, S. and Fritz, C. (2010), "Work characteristics, challenge appraisal, creativity, and proactive behavior: a multi-level study", Journal of Organizational Behavior, Vol. 31 No. 4, pp. 543-565.

Oprea, B., Iliescu, D., Burtăverde, V. and Dumitrache, M. (2019), "Personality and boredom at work: the mediating role of job crafting”, Career Development International, Vol. 24 No. 4, pp. 315-330.

Petrou, P., Bakker, A.B. and van den Heuvel, M. (2017), "Weekly job crafting and leisure crafting: implications for meaning-making and work engagement", Journal of Occupational and Organizational Psychology, Vol. 90 No. 2, pp. 129-152.

Podsakoff, P.M., MacKenzie, S.B. and Podsakoff, N.P. (2012), "Sources of method bias in social science research and recommendations on how to control it", Annual Review of Psychology, Vol. 63, pp. 539-569.

Prem, R., Ohly, S., Kubicek, B. and Korunka, C. (2017), "Thriving on challenge stressors? Exploring time pressure and learning demands as antecedents of thriving at work", Journal of Organizational Behavior, Vol. 38 No. 1, pp. 108-123.

Prouska, R., Psychogios, A.G. and Rexhepi, Y. (2016), "Rewarding employees in turbulent economies for improved organisational performance: exploring SMEs in the South-Eastern European region”, Personnel Review, Vol. 45 No. 6, pp. 1259-1280.

Quratulain, S. and Khan, A.K. (2015), "How does employees' public service motivation get affected? A conditional process analysis of the effects of person-job fit and work pressure", Public Personnel Management, Vol. 44 No. 2, pp. 266-289.

Rai, A. and Maheshwari, S. (2020), "Exploring the mediating role of work engagement between the linkages of job characteristics with organizational engagement and job satisfaction", Management Research Review.

Rogers, A.P. and Barber, L.K. (2019), "Workplace intrusions and employee strain: the interactive effects of extraversion and emotional stability", Anxiety, Stress and Coping, Vol. 32 No. 3, pp. 312-328.

Schaufeli, W.B., Salanova, M., González-Romá, V. and Bakker, A.B. (2002), "The measurement of engagement and burnout: a two sample confirmatory factor analytic approach", Journal of Happiness Studies, Vol. 3 No. 1, pp. 71-92.

Siemsen, E., Roth, A. and Oliveira, P. (2010), "Common method bias in regression models with linear, quadratic, and interaction effects", Organizational Research Methods, Vol. 13 No. 3, pp. 456-476.

Smith, M.M., Saklofske, D.H., Yan, G. and Sherry, S.B. (2017), "Does perfectionism predict depression, anxiety, stress, and life satisfaction after controlling for neuroticism?", Journal of Individual Differences, Vol. 38, pp. 63-70.

Sobol-Kwapinska, M. (2016), "Calm down-it's only neuroticism. Time perspectives as moderators and mediators of the relationship between neuroticism and well-being", Personality and Individual Differences, Vol. 94, pp. 64-71.

Sonnentag, S. and Kruel, U. (2006), "Psychological detachment from work during off-job time: the role of job stressors, job involvement, and recovery-related self-efficacy", European Journal of Work and Organizational Psychology, Vol. 15 No. 2, pp. 197-217.

Soomro, S.A., Kundi, Y.M. and Kamran, M. (2020), "Antecedents of workplace deviance: role of job insecurity, work stress, and ethical work climate”, Problemy Zarzadzania, Vol. 17 No. 6 (86), pp. 74-90.

Sosnowska, J., Hofmans, J. and De Fruyt, F. (2019), "Relating neuroticism to emotional exhaustion: a dynamic approach to personality", Frontiers in Psychology, Vol. 10, p. 2264. 
Tan, N., Yam, K.C. and Nai, J. (2017), "Workplace gossip prevalence on job performance: the mediating role of performance pressure", Academy of Management Proceedings, Vol. 2017, p. 15862, Academy of Management, Briarcliff Manor, New York, NY.

Tisu, L., Lupșa, D., Vîrgă, D. and Rusu, A. (2020), "Personality characteristics, job performance and mental health the mediating role of work engagement", Personality and Individual Differences, Vol. 153, p. 109644.

Tomaka, J., Blascovich, J., Kelsey, R.M. and Leitten, C.L. (1993), "Subjective, physiological, and behavioral effects of threat and challenge appraisal", Journal of Personality and Social Psychology, Vol. 65 No. 2, p. 248.

Tupes, E.C. and Christal, R.E. (1992), "Recurrent personality factors based on trait ratings", Journal of Personality, Vol. 60 No. 2, pp. 225-251, (original work published 1961).

Wang, N., Zhu, J., Dormann, C., Song, Z. and Bakker, A.B. (2020), "The daily motivators: positive work events, psychological needs satisfaction, and work engagement”, Applied Psychology, Vol. 69 No. 2, pp. 508-537.

Watson, D. and Clark, L.A. (1984), "Negative affectivity: the disposition to experience aversive emotional states", Psychological Bulletin, Vol. 96 No. 3, pp. 465-490.

Watson, D., Clark, L.A. and Tellegen, A. (1988), "Development and validation of brief measures of positive and negative affect: the PANAS scales", Journal of Personality and Social Psychology, Vol. 54 No. 6, pp. 1063-1070.

Webster, J.R., Beehr, T.A. and Love, K. (2011), "Extending the challenge-hindrance model of occupational stress: the role of appraisal", Journal of Vocational Behavior, Vol. 79, pp. 505-516.

Wihler, A., Meurs, J.A., Momm, T.D., John, J. and Blickle, G. (2017), “Conscientiousness, extraversion, and field sales performance: combining narrow personality, social skill, emotional stability, and nonlinearity", Personality and Individual Differences, Vol. 104, pp. 291-296.

Williams, L.J., Hartman, N. and Cavazotte, F. (2010), "Method variance and marker variables: a review and comprehensive CFA marker technique", Organizational Research Methods, Vol. 13 No. 3, pp. 477-514.

Xanthopoulou, D., Bakker, A.B., Demerouti, E. and Schaufeli, W.B. (2009), "Reciprocal relationships between job resources, personal resources, and work engagement", Journal of Vocational Behavior, Vol. 74 No. 3, pp. 235-244.

Zeigler-Hill, V., Vrabel, J.K., Sauls, D. and Lehtman, M.J. (2019), "Integrating motivation into current conceptualizations of personality", Personality and Individual Differences, Vol. 147, pp. 1-7.

Zhang, W., Jex, S.M., Peng, Y. and Wang, D. (2017), "Exploring the effects of job autonomy on engagement and creativity: the moderating role of performance pressure and learning goal orientation”, Journal of Business and Psychology, Vol. 32 No. 3, pp. 235-251.

\section{Further reading}

Bakker, A.B. and Demerouti, E. (2018), "Multiple levels in job demands-resources theory: implications for employee well-being and performance", in Diener, E., Oishi, S. and Tay, L. (Eds), Handbook of Wellbeing.

\section{Corresponding author}

Yasir Mansoor Kundi can be contacted at: yasir-mansoor.kundi@iae-aix.com 